\title{
Una crítica al antropocentrismo desde la ética ambiental
}

\author{
Víctor Hugo Salazar Ortiz \\ Universidad Autónoma de Aguascalientes \\ vhsalaza@correo.uaa.mx \\ Juan José Láriz Durón \\ Universidad Autónoma de Aguascalientes \\ jjlariz@correo.uaa.mx
}

\section{La discusión en torno al antropocentrismo en la ética ambiental}

Los promotores de la primera generación de ética ambiental propusieron que para que esta nueva disciplina fuera posible, era necesario crear una nueva ética o reformular la ya existente, pero para ello se tendría que dejar de lado la visión antropocentrista tradicional. Los representantes del pragmatismo ambiental no comparten la idea de que un antiantropocentrismo sea la solución que pueda favorecer un cambio en nuestra relación moral con el mundo natural; tampoco creen que el antropocentrismo tradicional, que sólo valora moralmente a los humanos, sus acciones y productos, sea el camino indicado. Lo que se ha visto es que esta naciente área de la filosofía debe hacerse sin abandonar los criterios éticos 
y morales tradicionales y que «no requerimos de una nueva ética, sino de la extensión de nuestra ética en cualquiera de sus variantes» (Herrera, 1990: 1), es decir, ampliarla de manera que puedan integrarse en ella estos nuevos asuntos y compromisos humanos con el mundo natural, no una nueva ética. Entonces, lo que varios pragmatistas ambientales plantean es que los ciudadanos, y especialmente los responsables de la gestión ambiental, pongan en práctica un antropocentrismo moderado, es decir, que además de poner atención en los valores humanos, también se atienda el valor propio de las especies naturales para dejar de valorarlas instrumentalmente sólo como materia prima o económicamente.

Por lo tanto, es importante revisar los antecedentes de cómo ha evolucionado la visión antropocentrista y poner al descubierto cuáles son los argumentos criticables de ésta, revelar las razones por las que los primeros filósofos ambientales solicitaron un cambio en la construcción y formulación de la ética para que ésta dejara de ser antropocéntrica. Tal propuesta parece resultar inviable, por no decir descabellada, pues ¿cómo ver y valorar el mundo desde una visión no antropocéntrica? Por otra parte, una vez que se ha tomado conciencia del impacto que ha provocado en la naturaleza la visión antropocentrista tradicional, tiránica y despótica, ¿no vendría bien generar un cambio, es decir, otro tipo de antropocentrismo?

\section{Antropomorfismo y antropocentrismo}

Una primera distinción que debe hacerse al abordar el análisis del antropocentrismo es que es diferente del antropomorfismo. Entiéndase por éste «conceder forma o cualidades 
humanas a una cosa» ${ }^{1}$. Esta definición no es del todo satisfactoria, pues una cualidad humana es estar vivo, y es compartida con animales y plantas, así que como lo indica Regan «lo que debe significar la definición es que antropomorfizamos si atribuimos a cosas no humanas una característica que pertenece sólo a los humanos [...] Antropomorfizar es hacer del objeto hablado más de los que es. Es hablar como si fuera como los humanos cuando no lo es» (1983: 7). Esta extensión de cualidades humanas a otras especies o cosas no generó problemas en el pasado, no obstante, a raíz de que se ha descubierto por conducto de la ética animal y ambiental un cargado sesgo antropocentrista, se requiere analizar y evaluar qué cualidades nos otorgan a los seres humanos derechos morales y cuáles compartimos con otras especies, lo que haría posible poder incluirlas en nuestro círculo moral. Es por ello importante distinguir el uso semántico que se hace del concepto antropomorfizar en los distintos contextos en que se emplean alusiones antropomórficas.

El antropomorfismo, de acuerdo con Herrera (2013), también puede compararse con el animismo, es decir, atribuir a los objetos naturales estados de ánimo que no poseen; por ejemplo, decir que un volcán está furioso. El punto que es importante destacar para él, es que el antropomorfismo era visto, de manera tradicional, sólo como una aplicación de cualidades netamente humanas a las cosas, pero señala: ¿qué pasa cuando, por ejemplo, se dice que «la Tierra se resiste a morir?» La cualidad de «estar vivo» no es privativa de la especie humana, de lo que resulta que «no todo animismo es un antropomorfismo ni es tampoco zoomorfismo»

1 Definición de la Real Academia Española en su Diccionario de la Lengua Española. Versión electrónica en http: / / dle.rae.es / ?id=2ytHwJZ 
(Herrera, 2013: 236). Herrera distingue, entonces, dos tipos de antropomorfismo, uno débil y otro fuerte. El primero de ellos, indica, se emplea de manera metafórica (por ejemplo, en las fábulas o en los dibujos animados actualmente) y es inocuo; el segundo, en cambio, posee carga filosófica, lo que obliga a utilizarlo con cuidado, principalmente porque presenta dos variantes. «La primera variante consiste en atribuir a los animales no humanos cualidades o propiedades humanas, mientras que la segunda variante consiste en atribuirles características o cualidades o propiedades exclusivamente humanas» (Herrera, 2013: 237). Desde el punto de vista de Herrera, la primera variante es trivial, ya que es obvio que compartimos con otras especies, concretamente con los animales, algunas cualidades como estar vivos, sentir, aprender, etc., y se puede hablar de posesión de ellas en algunos animales no humanos, sin incurrir en antropomorfismo. En cambio, la segunda variante, la que admite que hay cualidades exclusivamente humanas, como la capacidad de razonar, no puede aceptar que digan que algunos «animales no humanos razonan (pues) estaría cayendo, según esta versión, en el antropomorfismo» (Herrera, 2013: 238).

Esta distinción es la que origina la confusión y disputa entre el antropocentrismo y el no antropocentrismo, pues el antropocentrista criticará de antropomórfico a todo aquel que utilice cualidades exclusivamente humanas para comparar, partiendo de ellas, las capacidades de otras especies y negar su existencia o ponerles un límite, por no parecerse o alcanzar el nivel de las exclusivamente humanas.

El no antropocentrista se defenderá de la acusación replicando: primero, que antropocentrista es «quien piensa que sólo los humanos poseen características que los hacen el centro de toda consideración, especialmente la conside- 
ración moral» (Herrera, 2013: 239). Y éste no es su caso, pues lo único que busca el no antropocentrista es la comprensión de las capacidades de otras especies, como lo destaca y ejemplifica Herrera del trabajo hecho por Jane Goodall, quien para interpretar el comportamiento de los simios emplea conceptos análogos de cualidades y actitudes humanas para explicar la conducta de sus objetos de estudio, sin que con esto los quiera equiparar con humanos o, por no hacerlo así, muestre una falta de consideración moral hacia ellos ${ }^{2}$. Entonces, para el no antropocentrista, las cualidades y capacidades de los animales no humanos deben medirse y valorarse en función de ellas mismas y no comparándolas con algunas cualidades exclusivamente humanas, de lo contrario se cae, efectivamente, en una actitud antropocéntrica al poner como medida, para el reconocimiento de una cualidad o capacidad en otras especies, los niveles humanos y, en función de éstos, reconocer o no su existencia, estableciéndolo como criterio básico de valoración de ellas. En segundo lugar, el no antropocentrista podrá señalar que «no puede entregarse a la tarea de entender a otros seres vivos no humanos prescindiendo absolutamente de su aparato conceptual [...]. En este sentido, está condenado a ser ontológica y epistémicamente antropocéntrico, pues sólo puede pensar como humano» (Herrera, 2013: 239).

Lo que hay que destacar es que este hecho no limita ni impide a los seres humanos comportarse moralmente con

2 Tom Regan en The Case for Animal Rights hace referencia a un experimento hecho con primates que consistía en no emplear «expresiones antropomórficas» para explicar la conducta de estos animales. El resultado fue que era muy complicado, desordenado y poco objetivo describirlas y comprenderlas, así que se aceptó el uso de «expresiones antropomórficas» para describir la conducta y las actitudes de los primates (ver pp. 25-27). 
otras especies, pues «aunque epistémica y ontológicamente no podemos dejar de ser antropocéntricos, de ello no se sigue que tengamos que ser moralmente antropocéntricos» (Herrera, 2013: 239).

En suma, aunque el no antropocentrista sí incurre en cierto tipo de antropomorfismo, su finalidad no es demostrar y justificar la superioridad humana y con ello reotorgar a nuestra especie el poder de dominio sobre otras especies incurriendo en un antropocentrismo radical; antes bien, el objetivo puede ser un intento de comprender a otras especies empleando nuestros propios «anteojos conceptuales» (Herrera, 2013: 239.), lo que puede permitir un mejor conocimiento del mundo, y con ello salvaguardar el bienestar de otras especies.

La cuestión que sigue en duda es: ¿qué cualidades o capacidades necesita tener un ser para recibir consideración moral? De acuerdo con distintos pensadores, por lo menos dos deben ser las condiciones suficientes para que un ser pueda recibir consideración moral sin caer con ello en una actitud antropomórfica: sensibilidad y consciencia. La posesión de estas capacidades, en tanto cualidades propias del individuo, obligan a todo agente moral a tener consideración moral hacia todo ser que las posea. Así entonces, la aceptación y reconocimiento de estas cualidades en seres no humanos, específicamente en algunos animales, elimina el ser juzgado como antropomorfista; en cambio, el no aceptarlas, en tanto que no tienen el mismo alcance que las de los seres humanos, y no reconocer por esto la obligación que se tiene hacia ellos de otorgarles consideración moral, ésa sí es una actitud antropocentrista y es precisamente la que se debe combatir. 


\section{La visión antropocéntrica en la sociedad contemporánea}

La visión antropocéntrica que fue construyéndose a lo largo del pensamiento filosófico occidental, no deja lugar a dudas de que la especie humana fue sobrevalorada, en tanto que todas las demás se subvaloraron. Prácticamente hasta inicios del siglo XX nunca se consideró el invaluable valor de las entidades naturales y su importancia dentro de sus nichos ecológicos, sólo se vieron a los animales, las plantas, los ríos, la tierra, etc., como objetos de explotación, medios que están al servicio del hombre para cubrir y satisfacer nuestras necesidades e intereses. No obstante, hay que señalar que pese a que los seres humanos fueron sumamente inconscientes y egoístas hacia el mundo natural, no tenían ni tuvieron otra manera de interpretarlo, pues los proyectos humanos se erigieron como centro de sus anhelos y fueron el principal motor de sus ideas y sus acciones, aunque poco o nada se tomó consciencia del daño que causaban a las entidades naturales. No obstante, varias corrientes de ética ambiental se opusieron y se oponen radicalmente a la visión axiológica antropocentrista y plantean la posibilidad de construir una no antropocentrista, pues desde el punto de vista de éstas, como señala Miguel Estaban, aunque «la especie humana sea la única que delibera y valora no significa que los seres humanos seamos la única especie que tiene valor, y que por lo tanto debamos ser antropocéntricos, destinatarios últimos y únicos de nuestra valoración» (2013: 43). Esto es cierto, sin duda, pero como se verá más adelante, hay que distinguir entre un antropocentrismo epistémico y un antropocentrismo ético, algo que no hacen los antiantropocentristas, pues postulan un cambio de paradigma en la ética ambiental, pero no delimitan dichos ámbitos; 
esta postura es inadmisible, pues el antropocentrismo epistémico es incuestionable: «no podemos adoptar una visión no humana; el enfoque humano de la naturaleza está dado por nuestros mecanismos sensoriales y nuestra estructura neuromental» (Sagols, 2014: 60). Aunado a esta aclaración, podemos agregar lo que Teresa Kwiatkoswka y Jorge Issa señalan:

El antropocentrismo es la condición ontológica del hombre. No podemos entender el mundo y la vida desde una perspectiva que no sea la específicamente humana. Lo que para nosotros es la «realidad» se halla sujeto a nuestra propia interpretación; vale decir, está condenado a ser «humanizado». El mundo natural deviene, así, mundo cultural; esto es, un mundo que existe única y exclusivamente como objeto de transformaciones (1999: 262).

Hoy en día tenemos suficientemente claro que los seres humanos, a diferencia de todas las demás especies con las que compartimos el mundo, desarrollamos y aprovechamos históricamente la principal capacidad que nos diferencia y distingue de todas ellas: la razón. Haciendo uso de ésta, los primeros miembros de nuestra especie fueron transformando su entorno dándole nuevas formas y sentidos estéticos y culturales; comenzaron a crear también un mundo aparte de la naturaleza. A pesar de ello, este distanciamiento no era originalmente tan marcado, pues las nuevas comunidades humanas continuaban manteniendo un gran apego con el mundo natural y sus ciclos, pues vivían y organizaban sus vidas en torno a ellos. Sin embargo, con el transcurrir de los años, las personas fueron dejando de depender de manera directa de la naturaleza, aproximando los recursos vitales 
necesarios a sus comunidades por medio de construcciones (canales, presas, acueductos), de formas de producción (agricultura y ganadería) y modos de comercialización (mercados), provocando un distanciamiento de las personas respecto del mundo natural, que alcanzó su máximo nivel durante el siglo XX cuando la vida campirana tradicional cedió su lugar a ciudades modernas.

A partir del siglo XIX comenzaron a surgir sociedades capitalistas e industriales cada vez más fuertes y arrasadoras que fueron erigiéndose a la par del desarrollo técnico y científico. En estas nuevas y vastas zonas, los pobladores comenzaron a disfrutar de los beneficios del progreso y la modernización con novedosos medios de transporte y comunicación (trenes, vehículos, periódicos, telegramas, radio, teléfono, etc.); además, la vida cada día se volvió más cómoda, pues poco a poco empezó a contarse con servicios domiciliarios de agua, drenaje y electricidad. Al mismo tiempo que las ciudades y los servicios crecían, comenzaron los primeros problemas sociales y de contaminación ambiental.

Ahora bien, la solución a la problemática ambiental no es detener el progreso alcanzado por la humanidad hasta este momento, no tomar ya nada de la naturaleza y renunciar completamente a nuestra visión antropocéntrica, «como pretenden las ecoéticas radicales» (Sagols, 2014: 61), pues eso nos liquidaría. Indudablemente los seres humanos necesitamos recursos provenientes de la naturaleza para subsistir, y paradójicamente, sin su uso y los impactos ambientales que se producen con la extracción, producción y su distribución, careceríamos de los bienes alimenticios, energéticos y materiales que hacen posible nuestro sostenimiento y actual estilo de vida. El problema real no es que no se deba tomar lo que se necesita realmente de la naturaleza, sino cómo comenzó a 
hacerse y continúa haciéndose, es decir, sin principios éticos que consideren tanto el bienestar y beneficio de nuestra especie, así como la continuidad sustentable de otras especies y de la naturaleza en general.

Por lo anterior, parece claro que nuestra cosmovisión antropocéntrica tradicional requiere un cambio, mirar el mundo con una perspectiva moral más amplia, pues «reconocer que somos agentes morales equivale a admitir responsabilidad por aquellas consecuencias (previstas o no) de nuestra manipulación de la naturaleza que podrían llegar a afectar tanto el bienestar del individuo como el de la sociedad» (Kwiatkowska e Issa, 1999: 262).

Esta toma de conciencia de la conducta de nuestra especie con el mundo natural es la que ha llevado a filósofos ambientales de línea pragmática a elaborar propuestas menos extremas (como las de la primera generación de ética ambiental) y más acordes con los problemas actuales, sin tener que desplazar del todo la visión antropocéntrica del mundo, pero sí moderarla. Esta visión pragmática de los problemas ambientales, según explica Sagols (2014):

Busca actuar de manera racional, científica y democrática; es decir, tomar en cuenta los datos de la ciencia en vez de hacer especulaciones sobre los seres naturales y decidir, con base en un análisis racional y una puesta a discusión con los diversos sectores de la sociedad -en condiciones de igualdad e imparcialidad-, cuál es el uso respetuoso y ético que se puede hacer del medio ambiente en las diversas situaciones concretas (pp. 61 y 62).

Los representantes del pragmatismo ambiental, partiendo de lo dicho, proponen dos tipos de antropocentrismo, uno 
moderado que es abierto y busca una convergencia axiológica incluyente, tomando en cuenta lo señalado en la cita anterior, y otro que es nombrado por el filósofo Bryan Norton como antropocentrismo débil, que, a pesar de compartir los mismos criterios de racionalidad, cientificidad y democracia, no acepta que se reconozca en ellos un cierto tipo de valor inherente o intrínseco, que existe independientemente del conocimiento y la valoración humana; es decir, que tenga que descubrirse más que conocerse y construirse epistémicamente. La no aceptación a priori de este tipo de valor marca una importante diferencia entre la visión de los filósofos ambientales pragmatistas y Bryan Norton, a quien revisaré a continuación.

\section{La propuesta de Bryan Norton: un antropocentrismo débil}

En la discusión entre antropocentristas y no antropocentristas es necesario hacer un espacio para revisar la propuesta del distinguido filósofo ambiental Bryan Norton, quien postula un tipo especial de antropocentrismo que nombra antropocentrismo débil y donde muestra una oposición radical a varias de las propuestas de la primera generación de ética ambiental, particularmente de aquéllas que defienden que la ética ambiental debe elaborarse sobre la base de criterios no antropocéntricos.

Norton, en su artículo Environmental Ethics and Weak Anthropocentrism (1984), muestra por qué una visión opuesta al antropocentrismo, la defensa individual de entidades naturales y la aceptación de la existencia de valores intrínsecos en la naturaleza son propuestas erróneas para la construcción de la ética ambiental y para la formulación de principios 
que guíen el comportamiento de nuestra especie con otras y con el mundo natural en general.

Siguiendo el orden de su trabajo, Norton comienza señalado que el concepto antropocentrismo es ambiguo, ya que, por una parte, puede entenderse por éste que los seres humanos son el sitio (loci of value) y la fuente de reconocimiento de todos los valores; pero, de acuerdo con los no antropocentristas, algunos objetos no humanos se pueden designar como sitios de valor fundamental, es decir, como objetos que, independientemente del reconocimiento humano, poseen valor propio (intrínseco), con lo cual niegan o contradicen la centralidad axiológica humana. Lo anterior es rechazado por Norton, pues afirma que el cuidado y respeto de la naturaleza debe partir de los intereses humanos; somos los que debemos regular nuestra relación con el mundo natural. Asume que esto no da derecho a nuestra especie para destruirlo, como lo muestra con el ejemplo del «último hombre» (ver Norton, 1984: 133).

Norton propone superar la dicotomía que se presenta entre la postura antropocentrista y la no antropocentrista, mediante la puesta en práctica de un antropocentrismo débil, que comienza por distinguir las diferencias que hay entre un antropocentrismo fuerte (strong anthropocentrism) y un antropocentrismo débil (weak anthropocentrism). La característica principal del primero es que lo que se considera valioso, toma como referencia la satisfacción de las preferencias sentidas (felt preference), identificadas por él como «los deseos o necesidades de individuos humanos, que al menos temporalmente, pueden ser satisfechas mediante una experiencia específica de los mismos» (Norton, 1984: 134). Estas preferencias y su satisfacción se imponen sobre los de cualquier otra especie, sin que medie en ellas ningún tipo de consideración moral 
de las implicaciones causales de las acciones humanas ${ }^{3}$. El peligro de todo antropocentrismo fuerte para Norton, de acuerdo con la interpretación de la filósofa ibérica Carmen Velayos, «reside en su incapacidad para poner en cuestión las preferencias sentidas de los individuos, pues impide la discriminación entre sistemas de valor explotadores de la naturaleza y otros que no lo sean» (1996: 68). Esta falta de ponderación es la que lleva a las personas a actuar sin ningún marco de referencia ambiental, y a conducirse regidas por principios económicos y de consumo, guiadas únicamente por fines instrumentales, lo que impide cualquier tipo de consideración axiológica moral de la naturaleza. Ésta es la razón por la cual los grandes productores no se detienen ante nada: talan bosques, secan pantanos, modifican el curso de los ríos, no les preocupa socavar los ecosistemas hasta su destrucción, con el único fin de satisfacer un mercado de consumidores voraces. Norton considera injustificables estas prácticas que son auspiciadas por un antropocentrismo fuerte.

Un antropocentrismo débil se caracteriza, en cambio, por una visión más amplia del mundo, orientada por otro tipo de consideraciones a las que Norton nombra preferencias ponderadas (considered preference). Éstas son ciertas posturas que adopta la persona antes de actuar y aluden a «los deseos o necesidades que podrían ser expresados tras una cuidadosa deliberación, incluidos los juicios donde los deseos o necesidades son coherentes con una determinada visión del mundo; visión que incluye teorías científicas y un marco metafísico que las interprete como expresión de ideales estéticos y morales» (Norton, 1984: 134).

3 Este modo antropocentrista de ver el mundo fue calificado como chovinista por algunos (ver Richard and Val Routley, 1979), y como déspota por otros (ver John Passmore, 1998). 
A partir de esta distinción, Norton (1984) indica en qué consiste la diferencia axiológica que distingue a un antropocentrismo fuerte de uno débil.

Una teoría del valor es antropocéntricamente fuerte si todo el valor mostrado se explica por referencia a la satisfacción de las preferencias sentidas de los individuos humanos. Una teoría del valor es antropocéntricamente débil si todo el valor mostrado se explica por referencia a la satisfacción de alguna preferencia sentida de un individuo humano, la cual se extiende sobre los ideales existentes como elementos de una visión esencial del mundo para la determinación de preferencias consideradas (p. 134).

De acuerdo con lo señalado por Norton, las preferencias sentidas pueden ser racionales o no serlo. Las preferencias ponderadas, en cambio, son resultado de una reflexión meticulosa y concuerdan con una previa visión del mundo. Es a partir de éstas que el antropocentrismo débil proporciona, entonces, una base para criticar el sistema de valores que ve a las entidades naturales (bióticas y abióticas) sólo como objetos de explotación; y, por otra parte, puede servir como una guía de acción que controle el uso indiscriminado e inconsciente de los bienes naturales - poniendo especial cuidado en los no renovables-, de manera que nos hagamos cargo del fideicomiso natural que hemos heredado, lo que nos obliga a administrarlo «lo mejor posible guiándonos por preferencias consideradas y no sólo sentidas, es decir, deben predominar las preferencias deliberativas que toman en cuenta los efectos a largo plazo» (Sagols, 2011: 55). 
Esta visión ofrece, además, dos recursos éticos de importancia fundamental para el ecologismo. Primero, enfatiza la estrecha relación existente entre la especie humana y otras especies (respaldada por la teoría evolucionista), lo que sirve de base para criticar la visión antropocentrista dura que sólo valora a la naturaleza y a los animales no humanos utilizando como criterio exclusivo las preferencias/necesidades humanas. En segundo lugar, reconoce que las experiencias humanas (epistémicas, estéticas, culturales, etc.), resultado de un contacto cercano con el mundo natural, sirven para la conformación de valores ambientales críticos. Ambos recursos permiten remplazar las preferencias sentidas con éstas que son más racionales, lo que posibilita valorar la naturaleza, no sólo como un almacén del que tomamos o depredamos sus bienes y servicios, sino que podemos descubrir valores transformativos (transformative values) que modifican nuestros criterios axiológicos, de manera que la naturaleza ya no es vista sólo como un simple satisfactor de materias primas para producir bienes de consumo, sino que llega a ser una importante fuente de inspiración en la conformación de experiencias estéticas, ambientales, religiosas, etc., consideradas valiosas y de respeto (Norton, 2005: 306-307).

Lo que Norton propone, entonces, no es renunciar a nuestro antropocentrismo, sino que los seres humanos elaboremos una mejor y más amplia ponderación axiológica del mundo natural que no esté centrada únicamente en las preferencias humanas, sino que considere otros valores; se requerirá el reconocimiento de la variedad y diversidad de funciones que llevan a cabo los entes naturales, cuya existencia no está ni debería estar supeditada a nadie para beneficiar exclusivamente a la especie humana, sino al entorno, a través de la participación y colaboración en el equilibrio ecológico. 
Utilizaré un ejemplo para ilustrarlo. Tradicionalmente los seres humanos valoraron a las abejas por su miel y la cera, y se ignoró o se ponía poco interés en otra función que desempeñan y que es incluso más importante en términos ecológicos: la polinización ${ }^{4}$. Esta actividad no es exclusiva de las abejas, sino que es compartida por una cantidad indeterminada de insectos y por algunas aves. Sin embargo, los seres humanos, utilizando como único criterio el valor económico de sus productos agrícolas (felt preference), han sostenido una implacable e incesante lucha para controlar, y en la medida de lo posible exterminar, mediante el uso de insecticidas, todas aquellas plagas que puedan arruinar la productividad comercial ${ }^{5}$. Entonces, una teoría del valor centrada en un antropocentrismo débil, deberá elaborar una ponderación de estos métodos y de todo sistema de producción que sólo considere el bienestar humano, sacrificando a

$4 \quad$ El 90\% de las plantas del planeta requieren de un agente externo para reproducirse, ya que, a diferencia de los animales, no se pueden mover. De los polinizadores depende la producción de casi todos los frutos que comemos. La polinización podría hacerse manualmente, sólo que sería una labor terriblemente grande y millonaria, porque hay que hacerlo flor por flor para que dé fruto y, si queremos tener millones de frutos, hay que hacerlo millones de veces. Los polinizadores son servidores ambientales importantes para mantener la biodiversidad y lograr un alto rendimiento agrícola. Si se continúan realizando acciones que representen una amenaza para los polinizadores, por ejemplo, a través del uso intensivo de insecticidas, se pondrá en grave riesgo la existencia de éstos y la de nosotros al quedarnos sin este servicio ambiental (Ver Norandi, 2009).

5 Rachel Carson (2010 [1960]), en su obra Primavera silenciosa, advirtió de los peligros y las consecuencias que estas prácticas ocasionaban en el ambiente y en la cadena alimenticia, pues no sólo se provocaba la muerte de los insectos dañinos para los cultivos, sino en general de todo insecto sin importar si eran o no perjudiciales, pero además, al ser éstos el alimento básico de las aves éstas también morían de envenenamiento y progresivamente se iba ocasionando un daño en la cadena alimenticia llegando incluso a provocar problemas de salud en nuestra propia especie. Además, la muerte de las aves, producto de estas prácticas, da como resultado una primavera silenciosa, pues priva al bosque del canto de las aves y con ello se pierde ese elemento estético característico de estos lugares. Cabe señalar que este trabajo de Carson fue pionero y germen de los movimientos ambientalistas. 
los ecosistemas y a los seres vivos que lo habitan, y poniendo en riesgo su permanencia y supervivencia. Tal ponderación deberá basarse en criterios ecológicos, éticos y estéticos, mediante los cuales se expliquen y justifiquen las razones por las que nuestra relación con la naturaleza, y los seres vivos que en ella se encuentran, debe ser más responsable, de manera que pueda enmarcarse dentro de claros lineamientos legales y morales. De esta manera, no sólo se estará tomando en cuenta el bienestar humano, sino se considerará también, bajo un cierto holismo ambiental, el bienestar de toda la comunidad biótica a la que hacía referencia Leopold en su texto La ética de la tierra, indicándolo de la siguiente manera:

Dejemos de pensar en el uso decente de la tierra tan sólo como un problema económico. Examínese cada interrogante en términos de lo que ética y estéticamente es correcto, así como económicamente conveniente. Una cosa es correcta cuando tiende a mantener la integridad, la estabilidad y la belleza de la comunidad biótica; y es incorrecta cuando tiende a hacer lo contrario (Leopold, 1970: 262).

Hay un punto importante en esta discusión, pues tanto Norton como los eticistas ambientales, que están en contra del antropocentrismo $-\mathrm{y}$ a quienes se les suele calificar como antiantropocentristas-, no aclaran de manera explícita qué aspectos humanos están incluidos o excluidos en su crítica al antropocentrismo tradicional. Debido a lo anterior surgen discrepancias y desacuerdos, por lo que es importante aclarar que la crítica al antropocentrismo está dirigida exclusivamente al aspecto moral y no hacia la totalidad de nuestro ser, particularmente a nuestra capacidad racional, de manera 
que puede entenderse ésta como una crítica hacia el antropocentrismo moral, donde resulta que tener consideración moral hacia las entidades naturales no humanas no implica ponerse en contra de nuestra propia especie, más bien, debe exhortarnos a evaluar nuestra conducta ambiental desde este campo de reflexión, recientemente descubierto (ver Herrera, 2013a: 239).

Bajo este criterio puede señalarse, que tanto la visión moral «no antropocéntrica» como una «antropocéntrica débil» ofrecen un margen suficiente que permite poder reconocer los compromisos morales humanos hacia las entidades naturales, tradicionalmente acotados a los miembros de nuestra especie, y tener este tipo de consideración para aquéllas, ya sea hacia animales no humanos y / o seres vivos en general -en ambos casos considerados individualmente $o$ como especie, así como los ecosistemas- , y / o de igual manera considerados particular o globalmente. Visto el problema desde esta perspectiva, las diferencias pueden quedar zanjadas siguiendo el criterio pragmático establecido por William James (2002 [1907]), en el sentido de que si ambas posturas tienen un mismo objetivo, se modifica la cosmovisión moral antropocentrista tradicional (chauvinista, despótica o dura/ fuerte), para alcanzar este fin, independientemente de si comparten o no los mismos postulados teóricos ${ }^{6}$.

Lo anterior ha sido señalado por Norton (1991) en su libro Toward Unity among Environmentalist (Hacia la unidad de los ambientalistas) en el que enfatiza que tanto antropocentristas como ecocentristas tienen como «denominador común proteger los sistemas ecológicos», lo que demuestra que el

6 Ver Pragmatismo. Un nuevo nombre para algunos antiguos modos de pensar, Conferencia tercera «Algunos problemas metafísicos considerados pragmáticamente», pp. 67-86. 
«reconocimiento de un objetivo común por parte de los más diversos ambientalistas constituye un paso necesario para alcanzar un alto grado de efectividad en el propósito de proteger el medio ambiente» (Rozzi, 1997: 89).

Norton, en el mismo texto, agrega que es tiempo de superar las antiguas divisiones entre preservacionistas y conservacionistas, y tomar el ejemplo de las grandes figuras ambientalistas (Leopold y Carson), quienes buscaban el bien de la naturaleza como un fin en sí mismo; sin embargo, supieron reconocer que debían ser flexibles en sus argumentaciones para consiguierlo, privilegiando, en el terreno social y político, el bien que este cuidado de los entes naturales tiene para nuestra especie.

\begin{abstract}
Sin lugar a dudas Leopold y Carson han contribuido más que nadie a configurar el pensamiento de los ambientalistas actuales, y ellos compartían la voluntad de llegar con sus argumentos a instancias políticas relevantes. Ambos estaban profundamente comprometidos con una perspectiva biocéntrica y atacaron la arrogancia humana. Sin embargo, cuando se encontraban en arenas políticas enfatizaron siempre argumentos orientados hacia el bienestar humano ${ }^{7}$.
\end{abstract}

Lo importante, entonces, para avanzar unidos en la defensa común del medio ambiente, es buscar niveles de consenso que, de acuerdo con Ricardo Rozzi, deben encontrarse mediante dos vías: «primero, lograr que los ambientalistas que poseen diferentes cosmovisiones y sistemas de valores puedan adoptar políticas similares frente a problemas ambienta-

7 Norton, 1991, citado por Ricardo Rozzi, op. cit., p. 89 
les concretos; segundo, que los ambientalistas puedan generar una nueva 〈cosmovisión ecológica〉» (1997: 10).

\section{Conclusión}

El reconocimiento por parte de diferentes posturas ambientalistas de que la cosmovisión antropocentrista tradicional es parcial, puede ser visto como un primer avance en el consenso para que ésta se transforme en una visión que deje de ser opresiva, violenta y destructora hacia el entorno natural, y se adopte en su lugar un antropocentrismo débil que pondere de forma deliberativa el uso de los recursos naturales que necesitamos para subsistir. Lo anterior implica «la comprensión de la interdependencia entre los organismos vivos y su medio ambiente, [lo que] conduce al reconocimiento de la importancia que la diversidad biológica y los procesos ecosistémicos tienen para el ser humano y a la vez, el alto impacto que los seres humanos podemos tener sobre ellos» (Rozzi, 1997: 95). La necesidad de cuidar nuestra relación con el entorno, mantener su apropiado funcionamiento y colaborar cuando sea posible en la rehabilitación y restauración de los espacios naturales perdidos, de manera que haga posible su existencia y sirva de apoyo para la nuestra, y que con ello su y nuestra permanencia en este planeta se convierta en el «fundamento antropocéntrico» (Rozzi, 1997: 95) que guíe en lo sucesivo la relación de la especie humana con el mundo que la rodea. Además, una retórica orientada hacia el bienestar humano parece ser la mejor defensa argumentativa en el ámbito social y político para proteger la biodiversidad en la actualidad, en vez de negar nuestro antropocentrismo. 


\section{Bibliografía}

Carson, R. (2010 [1970]). Primavera silenciosa. Trad. Joandomènec Ros. Barcelona: Crítica.

Esteban, M. (2013). Naturaleza y conducta humana. México: Universidad de Quintana Roo/Conacyt.

Herrera Ibáñez, A. (1990). «Utilitarismo y ecología» en Estudios, No. 22 (otoño 1990), pp. 95-104. México: ITAM. . (2013). «El antropomorfismo y el no antropocentrismo» en González, J \& Linares, J (coords.) (2013), op. cit., pp. 234-244.

Kwiatkowska, T. \& Issa, J. (1999). «Ética ambiental, política y salud» en Vázquez, R. (comp.) Bioética y derecho, pp. 254-271. México: ITAM/ FCE.

Leopold, A. (1970 [1949]). «The Land Ethic» en Leopold, A. (1970 [1949]). A Sand County Almanac, pp. 237-264. New York: Ballantine Books.

Norandi, M. (2009). «La desaparición de los polinizadores, riesgo para la producción de alimentos» en La Jornada, martes 13 de enero de 2009 [versión digital http:/ / www.jornada.unam.mx/2009/01/13/index.php?secti on $=$ ciencias\&article $=a 02$ n1cie (revisada el 21 de octubre de 2016)]

Norton, B. G. (1984). «Environmental Ethics and Weak Anthropocentrism», en Environmental Ethics, Vol. 6, No. 2, pp. 131-148.

. (2005). «Values in Nature: A pluralistic Approach» en Cohen, A. I. \& Heath W. C. (2005). Op. cit., pp. 298-309. Passmore, John. (1978). La responsabilidad del hombre frente a la naturaleza. Madrid: Alianza.

Regan, T. (1983). The Case for Animal Right. Berkeley and Los Angeles, CA: University of California Press. 
Routley, R. \& Routley, V. (1979). «Against the Inevitability of Human Chauvinism» en Goodpaster, K. E. \& Sayre, K. M. (Eds.) (1979), op. cit., pp. 36-59.

Rozzi, R. (1997). «Hacia una superación de la dicotomía biocentrismo-antropocentrismo» en Ambiente y desarrollo, vol. XIII, No. 3 (septiembre), pp. 80-89, Santiago de Chile.

Sagols Sales, L. (2011). «El tabú de la sobrepoblación y la ética ambiental» en Theoría. Revista del Colegio de Filosofía, No. 23, junio 2011, UNAM, México, pp. 45-58. . (2014). La ética ante la crisis ecológica. México, D.F.:. Fontamara/UNAM.

Velayos, C. (1996). La dimensión moral del ambiente natural: ¿Necesitamos una nueva ética? España: Ecorama. 


\section{Resumen}

En este trabajo se parte de la discusión sostenida en torno al antropocentrismo entre dos vertientes de la ética ambiental: los puntos de vista de los primeros promotores de esta disciplina y el pragmatismo ambiental. Los fundadores de la ética ambiental proponen acabar con el monopolio antropocentrista mediante un no antropocentrismo o antiantropocentrismo; en tanto que los segundos, critican la imposibilidad y en su lugar proponen un antropocentrismo moderado o débil. Previamente a la exposición de estas propuestas, se revisa la distinción entre dos conceptos polémicos presentes en la discusión antropocentrista: el antropomorfismo y el antropocentrismo; posteriormente, se elabora una exposición sucinta de la visión antropocentrista que prevaleció durante gran parte del siglo $X X$ y, por último, se expone la propuesta antropocentrista de Bryan Norton, quien destaca que a pesar de que los seres humanos hemos sido bastante inconscientes en nuestro trato hacia las entidades naturales, no podemos dejar de lado nuestro antropocentrismo, pero sí podemos, en cambio, modificar nuestra visión tradicional, basada en un antropocentrismo duro, por una versión débil que sea más ponderativa.

Palabras clave: antropocentrismo, ética ambiental, pragmatismo ambiental.

\section{Abstract}

In this work we start with the discussion about anthropocentrism between two aspects of environmental ethics: the points of view of the first promoters of this discipline and environmental pragmatism. The founders of environmen- 
tal ethics propose to end the anthropocentric monopoly by means of a non-anthropocentrism or anti-anthropocentrism; While the latter, criticize the impossibility of this and instead propose a moderate or weak anthropocentrism. Prior to the presentation of these proposals, the distinction between two controversial concepts present in the anthropocentric discussion is reviewed: anthropomorphism and anthropocentrism; Later a brief exposition of the anthropocentric mink that prevailed during much of the 20th century is elaborated, and finally the anthropocentric proposal of Bryan Norton is exposed, who emphasizes that although we humans have been quite unconscious in our dealings with The natural entities, however, we can not leave aside our anthropocentrism, but we can, instead, modify our traditional vision, based on a hard anthropocentrism, for a weak version that is more ponderous.

Key words: anthropocentrism, environmental ethics, environmental pragmatism. 